\title{
BMJ Open Quality Reducing time to X-ray in emergency department ambulatory patients: a quality improvement project
}

\author{
Matthew Mo Kin Kwok, ${ }^{1,2,3}$ Allison Chiu, ${ }^{3}$ James Chia, ${ }^{4}$ Cindy Hansen ${ }^{1,4}$
}

To cite: Kwok MMK, Chiu A, Chia J, et al. Reducing time to X-ray in emergency department ambulatory patients: a quality improvement project. BMJ Open Quality 2021;10:e000995. doi:10.1136/ bmjoq-2020-000995

Received 10 April 2020 Revised 17 April 2021 Accepted 21 April 2021
Check for updates

(C) Author(s) (or their employer(s)) 2021. Re-use permitted under CC BY-NC. No commercial re-use. See rights and permissions. Published by BMJ.

${ }^{1}$ Department of Emergency Medicine, Richmond Hospital, Vancouver Coastal Health, Richmond, British Columbia,

Canada

${ }^{2}$ Department of Emergency Medicine, The University of British Columbia, Vancouver, British Columbia, Canada ${ }^{3}$ Physician Led Quality Improvement, Vancouver Coastal Health Authority, Vancouver, British Columbia, Canada

${ }^{4}$ Team Based Quality Improvement, Vancouver Coastal Health, Vancouver, British Columbia, Canada

Correspondence to Dr Matthew Mo Kin Kwok; Matthew.kwok@vch.ca

\section{ABSTRACT}

This quality improvement project began when physicians and nurses at our hospital observed patients waiting for excessive periods of time for a porter to escort patients from the emergency department (ED) to medical imaging (MI). However, certain patients may not need staff escort and are able to ambulate from ED to MI by themselves. This would reduce waiting time from when the $X$-ray is ordered to $X$-ray being done, which may reduce overall ED length of stay and improve patients' experience.

Our project aim is to decrease the time to X-ray by $50 \%$ within 6 months by having appropriate ambulatory patients walk from the ED to the X-ray department without a porter. To achieve our goal, several strategies were employed. First, brainstorm sessions were held to better understand the barriers and ways to implement the new process. Second, a patient survey was conducted to understand their thoughts on the change idea. Third, data were collected to assess the inefficiency problem on the number of times non-porter staff escorted patients due to porters being unavailable. A total of 14 PDSA (Plan-Do-Study-Act) cycles were completed between December 2018 and May 2019. A human factor specialist was consulted to examine the process for safety and optimisation of the patient journey.

In our PDSA cycles, self-ambulatory patients were compared with ambulatory patients who required an escort. An improvement was found from time to X-ray of $28 \mathrm{~min}$ (11 $\mathrm{min}$ vs $39 \mathrm{~min}$ ). The new self-ambulatory process was implemented in June 2019 on a daily basis.

\section{INTRODUCTION}

Our hospital setting is a university-affiliated community teaching hospital located in British Columbia, Canada. It has annual emergency visits of approximately 60000 . As a hospital policy, all emergency department (ED) patients, including ambulatory patients, required an escort to medical imaging (MI) when an X-ray was ordered. When porters were not available, an ED or MI staff would frequently escort patients back and forth between ED and MI. This process unnecessarily created barriers and additional steps in patients' journey in receiving X-rays. In turn, it lengthened time to diagnosis, time to treatment and ED length of stay.

\section{BACKGROUND}

ED wait time has been acknowledged as a major barrier to timely and accessible emergency care. ${ }^{1-4}$ This is associated negatively with objective clinical endpoints, such as mortality, as well as other clinically important processes of care. ${ }^{5}$ The problem of increased ED wait time is believed to be multifactorial. It has been suggested that one of the reasons is increased utilisation of $\mathrm{MI}$ in the ED. ${ }^{6}$ A survey conducted in the USA found that $46.8 \%$ of ED patients underwent MI in the $\mathrm{ED}^{7}$ and patients receiving $\mathrm{MI}$ diagnostics have a significantly longer ED length of stay. ${ }^{89}$ Attempts have been made to improve access to radiology and decrease wait time in patients' journey in the ED. For example, Hitti et al used LEAN change management techniques to reduce transportation time to plain radiology in the $\mathrm{ED} .{ }^{10} \mathrm{In}$ this study, the LEAN methodology was employed to improve the transportation part of the process of radiology turnaround time in the ED. Two main changes were made. First, a dashboard was created to display all new requests for MI. Second, a dedicated transporter was assigned with no other responsibilities beyond patient transport back and forth to the radiology room from the ED. These interventions resulted in a decrease in mean transport time of $22.89 \mathrm{~min}-9.87 \mathrm{~min}$.

At our hospital, we also would like to decrease the overall radiology turnaround time in our ED patients. This quality improvement project aims to decrease the transportation time and time to X-ray after being ordered by $50 \%$ within 6 months by having appropriate ambulatory patients walk themselves in this process without a hospital escort.

\section{MEASUREMENT}

This quality improvement project was to determine the feasibility of ambulatory patients independently walk from ED to MI. The primary quantitative endpoint measured was time from X-ray order to X-ray completed. 


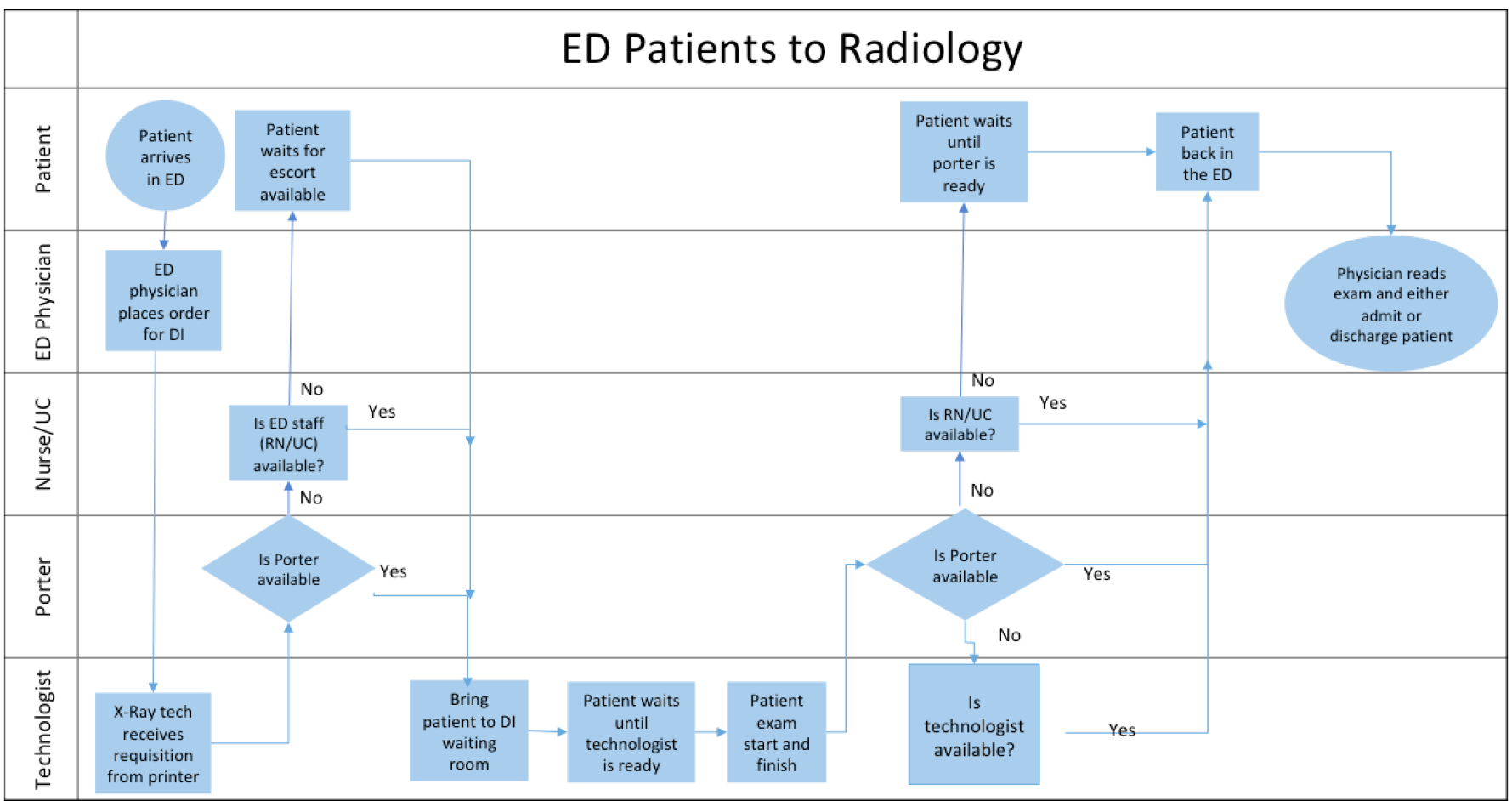

Figure 1 Process map demonstrating patients' journey from the emergency department (ED) to medical imaging. RN, Registered Nurse; UC, Unit Clerk; DI, Diagnostic Imaging.

Qualitative data were also collected to determine the benefits and counterbalances of the proposed process.

During each Plan-Do-Study-Act (PDSA) cycle, data were collected during the patient journey. Data were collected and tracked by the emergency physicians and technologists. Ambulatory patients who required an upper extremity X-ray were used in our testing cohort and ambulatory patients where chest X-ray was ordered underwent usual care as a control group. Once the inclusion-exclusion criteria were developed, data were also extracted from the electronic medical record system and longitudinal data were analysed.

\section{BASELINE MEASUREMENT}

Baseline data were collected through the creation of a process map, inefficiency tally, patient survey and project brainstorm sessions.

\section{Process map}

We began by creating a process map. Figure 1 illustrates the patient journey map prior to project start. We observed that there are multiple non-essential steps in the process. This, in turn, created barriers and unnecessary wait time for patients in obtaining an X-ray.

\section{Inefficiency tally}

Baseline data were collected on the number of times per week where porters were too busy to escort patients from ED to MI resulting in other staff (nurses or technologists) escorting patients. We found that in a 1-week period, ED nurses escorted patients between ED and MI 116 times and MI technologists escorted patients 192 times.

\section{Patient survey}

A patient survey was also conducted with ED patients to understand the benefit or concerns they may have from their perspective. Patients responded overwhelmingly wanting to independently walk to the radiology themselves seeing the benefit of time-saving, including:

- [patients] can access the service faster. Most patients have a family member with them who can help with a transfer to x-ray'

- 'I guess it could speed things up which is probably good for a number of reasons. (i.e. frees personnel for more important stuff, less waiting time $\rightarrow$ less anxiety?)'

- 'if you are well enough to do it why not. The faster you get tests done the faster you and others get moving towards going home faster'.

- 'gives the patient independence. It does not require the time of an escort who may likely have other things to do. It could speed up the process of getting an x-ray'

- 'speed up the process. free up nurses' time. leave porter more time to care for those who need it'

\section{Brainstorm sessions}

Three 1-hour brainstorm sessions were held to better understand staff perceptions of challenges and barriers to patients walking from ED to MI without an escort and brainstorm solutions together. Concerns and solutions were documented and shared with staff. Concerns 
mainly surrounded security and patient safety. Would the new process present new security and safety issues for the staff? Would patients get lost in the hospital through the new process? Would there be increased clinical risks for patients? Solutions implemented included increase closed-circuit cameras, barn door barriers and punch code door locks to improve security. In addition, wall signs and directional tapes were placed to guide patients' journey between ED and MI. A thorough discussion was made concerning the appropriate patients who would be included in this new process in order to mitigate clinical risks. It was agreed on that only clinically stable patients would be eligible to be part of the new process. We defined clinically stable patients as those with stable vital signs, not flagged as violent and not considered fragile by the most responsible physician.

\section{DESIGN}

This project used a collaborative approach to design our quality improvement intervention. Baseline measurements were used to inform the PDSA and requirements for each PDSA cycle. We used interim data collection to inform each subsequent cycle.

Our first intervention was to increase awareness of the project idea to improve the patient journey experience and reduce the workload on staff to escort patients. The results obtained from our baseline workflow diagram and patient survey results were disseminated and share at staff meetings in the ED and MI department. The project was also discussed and shared at the hospital quality council meetings attended by frontline and administration staff to further increase awareness and support of the project.

\section{STRATEGY AND RESULTS PDSA 1}

In our first PDSA, the project lead physician and technologist were on staff in the ED and MI, respectively. Groundwork signage was put up on the walls to direct patients from the ED to MI. A trial of four patients walked independently. They were ambulatory stable patients with chest X-rays or upper extremity X-rays ordered. Difficulties were found with the patients not knowing how to walk back to the ED from MI, as well as access issues since certain doors were locked. Therefore, we examined other routes for patients to walk between the ED and MI. As a result, an alternative route was chosen for the next PDSA cycles.

\section{PDSA 2-3}

The second set of PDSAs started with no significant issues in regard to the alternative route chosen. However, staff was still apprehensive from a patient safety standpoint. Safety concerns were especially raised in relation to potential clinical status deterioration. Although we wanted to have all ambulatory patients walk between ED and MI, it was decided that we would only allow very lowrisk patients to be involved in this self-ambulatory process.
Therefore, we further excluded patients who received narcotics in the ED in the new process. In addition, we limited our inclusion criteria to only stable patients with upper extremity X-rays ordered due to upper extremity injuries. Upper extremity X-rays were defined as X-rays of the fingers, hand, wrist, forearm, elbow, humerus, shoulder or clavicle.

Some hospital doors were locked after 20:00 and the project team decided to confine the hours of this project to 08:00-20:00. Also, additional signage was posted in the MI waiting room to inform patients to be seated and wait for their names to be called. Furthermore, patients were informed that they will be seen in order of priority and not in the order they sat down. Clearer patient inclusion and exclusion criteria in the process were established for the next PDSA cycles.

\section{PDSA 4-14}

A clear inclusion/exclusion criteria poster was developed and posted in the ED and MI staff areas (figure 2). We started employing the new self-ambulatory process with different emergency staff and MI staff at different times of the day in each PDSA. The project team huddles with ED and MI staff before each PDSA cycle. This allows for all staff to be clear about which ED patients are eligible to walk to MI independently without a porter. It also informed staff regarding key information to communicate to patients. We also documented knowledge gained from each PDSA cycle to improve the process. Minor changes were made from the learnings after each PDSA cycle. These included:

- Signage to direct patients between the ED and MI. We initially used arrow posters to direct patients. The colour of the posters and the location of where the posters were placed evolved between PDSA cycles in an attempt to improve direction. In the end, brightline tapes on the wall were found to be the most effective way of directing patients between ED and MI.

- Security and safety. During this set of PDSA cycles, additional security cameras were placed in strategic locations so that patients journeying between ED and MI could be closely monitored. Furthermore, additional sliding barn doors and punch code locks were placed so that patients would not enter restricted areas.

- Electronic X-ray ordering procedures. Modifications were made in the physician order entry procedures so that patients who were self-ambulating, versus those who were not self-ambulating, between ED and MI, can be more easily identified.

Data were collected to measure whether an improvement was made by comparing self-ambulatory patients with ambulatory patients with an escort. We compared the time from X-ray ordered to the time to X-ray complete between stable ambulatory patients who needed an upper extremity X-ray with the new process (self-ambulation) versus stable ambulatory patients who needed a chest X-ray with the old process (escorted by a porter). Patients 


\section{ED-MI Walker's Project}

\begin{tabular}{|ll}
\hline Inclusion Criteria & Exclusion Criteria \\
$\square$ Upper Extremity \\
injury needing X- \\
Ray & $\times$ Non-upper extremity \\
& $\times$ Received narcotics \\
& $\times$ Violent \\
& $\times$ Fragile \\
&
\end{tabular}

What to tell the patient:
- WAIT in X-Ray
- You will be called in once technologist is
available
- Return to ED and tell the Unit clerk if you have
any concerns
- If there is a life-threatening emergency, pull
alert cord in X-ray washroom (there is a notice
in X-Ray)

\section{ED-MI Walker's Project}

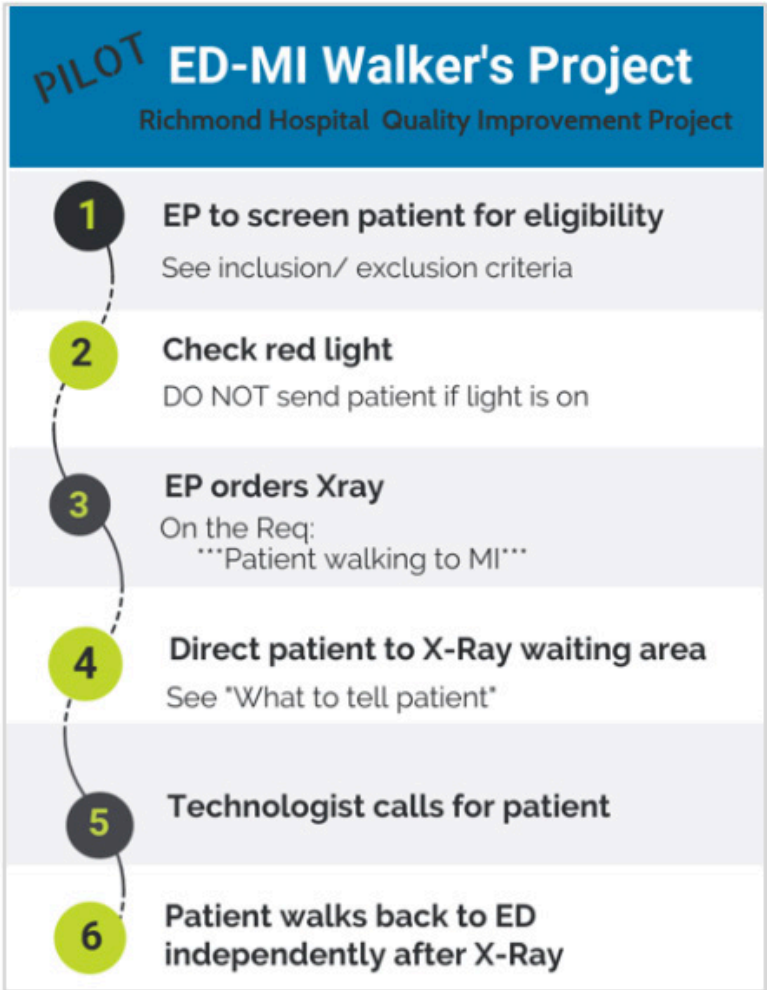

Figure 2 Staff information poster. ED, emergency department; EP, emergency physician; MI, medical imaging.

who went through the old process, our control group, had the same exclusion criteria except for the modality of X-ray ordered. A comparison was made during the same predefined period of time during the PDSA cycle in an effort to mitigate other factors which may affect the time to X-ray. In a sample size of 54 patients, we found a shorter time to completion of X-ray after ordering between the self-ambulation new process and the escorted by a porter old process of $28 \mathrm{~min}$ (11 $\mathrm{min}$ in the self-ambulatory patients vs $39 \mathrm{~min}$ in the escorted patients).

\section{Human factors assessment}

Formal human factors and risk assessment was done to provide any recommendations relating to patient safety, human error and efficiency within the process. Several changes were made during the PDSA cycles which included signage locations, communications to patients and communication strategies between ED and MI.

We had multiple team meetings to address concerns and to discuss ways to improve during the PDSA cycles. Staff became more comfortable with patients selfambulating between ED and MI. Both the ED and MI department were agreeable to a daily implementation of the new process. We were able to implement the new selfambulatory process on a daily basis 6 months after the initial PDSA.

\section{Post implementation assessment}

A post implementation survey was given to ED patients who participated in the new process at our hospital by walking themselves from the ED to the radiology department for an X-ray. A total of 11 surveys were completed.
A majority of patients $(n=10,91 \%)$ liked the new process. None of the surveyed patients encountered any difficulties in the new process. We also received positive anecdotal feedback from ED and MI staff. There were plans to expand the new self-ambulatory process to patients who needed chest X-rays. However, because of the COVID-19 pandemic, the expansion was put on hold.

\section{LESSONS AND LIMITATIONS}

Overall, our intervention has been successful and ambulatory patients are now walking independently from ED to MI. We learnt many lessons from this QI project. The culture of a team is very important and having a robust change management plan is critical. At the start, there was significant resistance to change from the status quo. As this project idea had been tried a few years in the past, there was already a preconceived notion of project failure. But after multiple staff meetings, and informational discussions, staff felt heard, and concerns alleviated. Staff became comfortable trialling each PDSA cycle slowly over time.

A few unexpected but positive aspects were also addressed by this QI project. Through the engagement sessions, it was found that staff, at times, felt unsafe in their work environment. The brainstorm sessions allowed staff to state their concerns in a safe space. For example, we learnt that issues such as lack of a locked door in the staff room and open hallways at night have led to an uncomfortable work environment. During the PDSA phase of the project, several infrastructure changes were implemented. This included increase closed-circuit cameras, 
barn door and punch code door locks to improve security. As a result, the project has unintentionally increased the feeling of staff safety, especially during the evening and overnight shifts.

\section{CONCLUSIONS}

Process change takes strategic planning and actions. We report our experience in changing the process at our hospital and have appropriate ambulatory patients walk from the ED to the X-ray department without staff escort in an attempt to decrease inefficacies and wastage in our system. By employing techniques of patient surveys, staff misuse assessment, group brainstorming meetings, PDSA's and human factor assessment, we were able to change the process of how ED patients obtain X-ray at our hospital.

Twitter Matthew Mo Kin Kwok @kwok_matthew

Contributors MMKK came up with the project idea, planned the project, led the project and contributed to the writing and editing of the manuscript. AC took part in the planning/execution of the project and contributed to the writing and editing of the manuscript. JC took part in the planning/execution of the project and contributed to the writing and editing of the manuscript. $\mathrm{CH}$ took part in the planning/execution of the project and contributed to the writing and editing of the manuscript.

Funding The authors have not declared a specific grant for this research from any funding agency in the public, commercial or not-for-profit sectors.

Competing interests None declared.

Patient and public involvement Patients and/or the public were not involved in the design, or conduct, or reporting, or dissemination plans of this research.

Patient consent for publication Not required.
Provenance and peer review Not commissioned; externally peer reviewed.

Open access This is an open access article distributed in accordance with the Creative Commons Attribution Non Commercial (CC BY-NC 4.0) license, which permits others to distribute, remix, adapt, build upon this work non-commercially, and license their derivative works on different terms, provided the original work is properly cited, appropriate credit is given, any changes made indicated, and the use is non-commercial. See: http://creativecommons.org/licenses/by-nc/4.0/.

\section{REFERENCES}

1 Bond K, Ospina MB, Blitz S, et al. Frequency, determinants and impact of overcrowding in emergency departments in Canada: a national survey. Healthc Q 2007;10:32-40.

2 Pines JM, Hilton JA, Weber EJ, et al. International perspectives on emergency department crowding. Acad Emerg Med 2011;18:1358-70.

3 Pitts SR, Pines JM, Handrigan MT, et al. National trends in emergency department occupancy, 2001 to 2008: effect of inpatient admissions versus emergency department practice intensity. Ann Emerg Med 2012;60:679-86.

4 Vermeulen MJ, Stukel TA, Guttmann A, et al. Evaluation of an emergency department lean process improvement program to reduce length of stay. Ann Emerg Med 2014;64:427-38.

5 Bernstein SL, Aronsky D, Duseja R, et al. The effect of emergency department crowding on clinically oriented outcomes. Acad Emerg Med 2009;16:1-10.

6 Mills AM, Raja AS, Marin JR. Optimizing diagnostic imaging in the emergency department. Acad Emerg Med 2015;22:625-31.

7 National Hospital Ambulatory Medical Care Survey: 2011 Emergency Department Summary Tables. Available: https://www.cdc.gov/nchs/ data/ ahcd/nhamcs_emergency/2011_ed_web_tables.pdf

8 Goloback M, McCarthy DM, Schmidt M, et al. Ed operational factors associated with patient satisfaction. Am J Emerg Med 2015;33:111-2.

9 Ryan A, Hunter K, Cunningham K, et al. Steps: lean thinking, theory of constraints and identifying bottlenecks in an emergency department. Ir Med J 2013;106:105-7.

10 Hitti EA, El-Eid GR, Tamim H, et al. Improving emergency department radiology transportation time: a successful implementation of lean methodology. BMC Health Serv Res 2017;17:625. 